\title{
Strong diel redox cycle of manganese in the surface Arctic Ocean
}

\author{
YANG XIANG, PHOEBE J. LAM AND JONG-MI LEE
}

University of California, Santa Cruz

Presenting Author: yaxiang@ucsc.edu

Manganese $(\mathrm{Mn})$ is the $3^{\text {rd }}$ most abundant transition metal in Earth's crust and exists in three oxidation states (II, III, and IV) in the ocean. Oxidation from dissolved $\mathrm{Mn}$ (II) to particulate $\mathrm{Mn}(\mathrm{III} / \mathrm{IV})$ oxides is known to be microbially mediated through direct or indirect pathways (e.g., Tebo et al., 2004; Learman et al., 2011), and the product, Mn(III/IV) oxides, is one of the strongest natural oxidants and known as the "scavengers of the sea" (Goldberg, 1954). Thus, chemical speciation of particulate $\mathrm{Mn}(\mathrm{pMn})$, which is characterized by different oxidation and adsorption capabilities (Lee et al., 2021), is essential to understand the biogeochemical cycling of $\mathrm{Mn}$ and other particlereactive elements. However, there have been few studies on the speciation of $\mathrm{pMn}$ in the ocean outside of hydrothermal environments, and none in the Arctic ocean. Here, we present the average oxidation state (AOS) of pMn from the upper $25 \mathrm{~m}$ water column collected during the U.S. GEOTRACES Arctic cruise (GN01) in 2015 that were measured using synchrotronbased X-ray absorption spectroscopy. The GN01 cruise took place in late summer, experiencing various levels of day-night cycles, including 24-hour light condition. We find that the pMn AOS has a positive correlation with the solar zenith angle (SZA), the angle between the sun and the vertical plane. Generally, the pMn AOS is more oxidized during the dark polar night (SZA $>$ $\left.90^{\circ}\right)$, whereas it is more reduced during the day $\left(\mathrm{SZA}<90^{\circ}\right)$. Our results indicate active redox variations of pMn during the daynight cycle, which takes place in the cold (near freezing) and stratified polar mixed layer. Future measurements of trace elements and their isotopes (TEIs) during the polar winter with 24-hour darkness are necessary to explore the significance of $\mathrm{Mn}$ oxidation in the dark and how this process influences other TEIs on a seasonal and annual time scale. The oxidation of dissolved $\mathrm{Mn}(\mathrm{II})$ in the extended polar winter, if it exists, could serve as an important source of dark brown layers of $\mathrm{Mn}(\mathrm{III} / \mathrm{IV})$ oxides observed in the sedimentary records of the central Arctic Ocean (e.g., Löwemark et al., 2014; März et al., 2011). 